УДК 620.9.001; 620.97

\title{
ВКЛАД ГЕОТЕРМАЛЬНОЙ ЭНЕРГЕТИКИ В ЭНЕРГЕТИЧЕСКУЮ НЕЗАВИСИМОСТЬ УКРАИНЫ
}

\author{
Долинский А.А., д.т.н., академик НАН Украины, почетный директор ИТТФ НАН Украины, \\ Резакова T.А., канд. техн. наук
}

Институт технической теплофизики НАН Украины, ул. Желябова, 2а, Киев, 03680, Украина

У структурі енергетичного балансу України частка імпорту енергоресурсів перевищує власний їх видобуток і виробництво, що ставить країну в серйозну залежність від імпорту, незважаючи на те, що Україна має всі можливості повністю забезпечити себе енергією. Для цього необхідно підвищувати рівень енергоефективності та сприяти поширенню використання екологічно чистих технологій відновлюваної енергетики зокрема геотермальної енергії. Геотермальна енергетика $є$ усталеною і відносно зрілою формою комерційного використання поновлюваних джерел енергіï. Важливою характеристикою $\epsilon$ фактор високого навантаження, що означає, що кожен МВт потужності виробляє значно більше електроенергії протягом року ніж МВт вітру або сонячного потенціалу.

Бібл. 11, рис. 2, табл. 3.
В структуре энергетического баланса Украины доля импорта энергоресурсов превышает собственную их добычу и производство, что ставит страну в серьезную зависимость от импорта, несмотря на то, что Украина имеет все возможности полностью обеспечить себя энергией. Для этого необходимо повышать уровень энергоэффективности и способствовать распространению использования экологически чистых технологий возобновляемой энергетики, в частности геотермальной энергетики. Геотермальная энергетика является устоявшейся и относительно зрелой формой коммерческого использования возобновляемых источников энергии. Важной характеристикой является фактор высокой нагрузки, что означает, что каждый $\mathrm{MBT}$ мощности производит значительно больше электроэнергии в течение года чем МВт ветра или солнечного потенциала.
In the structure of the energy balance of Ukraine, the share of energy imports exceeds their own production and production, which puts the country in a serious dependence on imports, despite the fact that Ukraine has all the possibilities to fully provide itself with energy. To do this, it is necessary to increase the level of energy efficiency and promote the use of environmentally friendly renewable energy technologies in particular geothermal energy. Geothermal energy is an established and relatively mature form of commercial use of renewable energy sources. One of the important characteristics is the high load factor, which means that each MW of power produces significantly more electricity during the year than MW of wind or solar capacity.

Ключевые слова: энергетический баланс, угольные ресурсы, геотермальная энергетика.

Энергетическая независимость страны определяется стабильным и экономически выгодным обеспечением энергокомплекса топливными ресурсами - угля и газа для производства электрической и тепловой энергии.

Важным критерием надежности энергосистемы является показатель импортозависимости, что определяется как доля импортных компонентов в ОППЭ. В 2016 г. этот показатель составил $51,6 \%$, что говорит о серьезном риске для энергетической безопасности. Поэтому, вопрос уменьшения импортозависимости чрезвычайно важен и актуален для Украины. В связи с уменьшением добычи угля из-за военных действий на Донбассе фактор угроз энергетической и экономической безопасности страны возрастает.

Угольный рынок Украины характеризуется специфическими условиями производства и большой территориальной разбросанностью угледобывающих, углеперерабатывающих предприятий. Добыча и переработка угля в Украине осуществляется преимущественно в Донецком, Львовско-Волынском угольных и Приднепровском буроугольном бассейнах.

Фактическое отсутствие угля антрацитовой группы на тепловых электрических станциях, работающих в основной части ОЭС Украины, вынуждает максимально интенсифицировать работу энергоблоков ТЭС, переводить их на газовую группу угля, сокращать объем и количество планово - предупредительных ремонтов, что может привести к повышенной аварийности, незапланированным ремонтам, несбалансированности работы энергоблоков и, как следствие, применять меры по принудительному ограничению потребления.

Доля электроэнергии, произведенной с использованием угольной продукции, составляет около одной четверти общего производства электроэнергии. Около $45 \%$ энергоблоков украинских ТЭС (по установленной мощности) работают на угле антрацитовой группы, около $35 \%$ - на угле газовой группы, и около $20 \%$ - на газе.

В течение 2001-2013 гг. в Украине ежегодно добывалось около 80 млн. т необработанного (рядового) угля, около $2 / 3$ которого используется в электро- и теплоэнергетике. По данным Министерства энергетики и угольной промышленности [1], в 2015 г. объем добычи угля в Украине составил 39,7 млн. т, что на 38,8 \% меньше по сравнению с 2014. Потребление энергетиче-ского угля на украинских теплоэлектростанциях в 2015 году сократилось на треть по сравнению с предыдущим годом - до 27 млн. тонн. Производство тепловой генера- 
ции уменьшилось, спрос на уголь снизился с 38 млн. тонн до 27 млн. тонн [1].

Из-за сокращения собственной добычи угля в 2015 г. примерно на 40 \%, Украина была вынуждена наращивать его импорт.

Министерство энергетики и угольной промышленности констатирует, что в январе 2017 года на украинские теплоэлектростанции (ТЭС) было поставлено 93,5 тысячи тонн энергетического угля из России, что составило 57,2 \% от общего объема импортных поставок [2].

В январе-феврале 2017г. Украина импортировала 2 млн. 463,529 тыс. т каменного угля и антрацита (табл. 1): из РФ поступило угля доля в импорте $69,1 \%$, из США доля в импорте $18,3 \%$, из Казахстана - доля 5,7 \%, из других стран - доля 6,9 \% (рис. 1, а). Таким образом, импорт угля и антрацита за этот период вырос в 2,1 раза по сравнению с январем-февралем 2016 [2, 3, 4].

Табл. 1. Общая добыча угля в Украине

\begin{tabular}{|l|c|c|}
\hline \multicolumn{1}{|c|}{ Тип угля } & Декабрь 2016 год & Январь 2017 год \\
\hline Энергетический уголь, млн. т & 2,5 & 3,1 \\
\hline Коксовый уголь, млн. т & 0,7 & 0,6 \\
\hline Всего по Украине & 3,2 & 3,7 \\
\hline
\end{tabular}

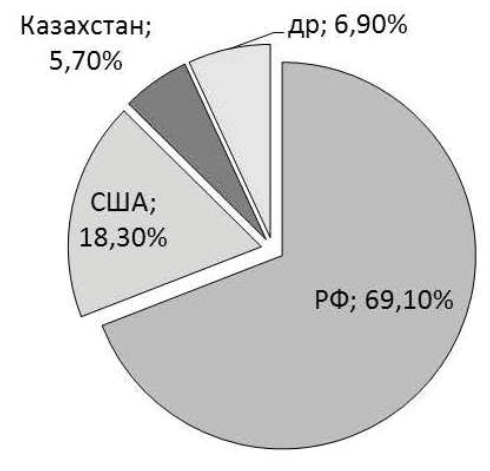

a)

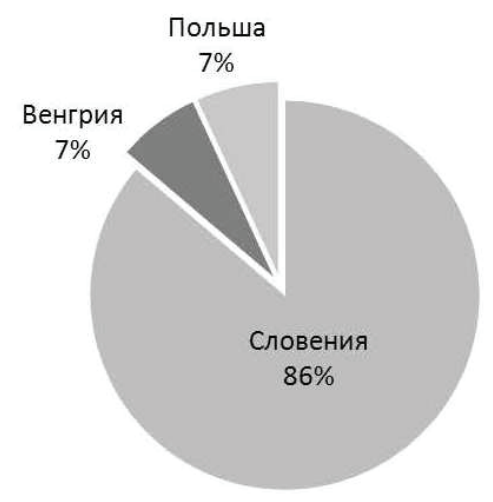

б)

Рис. 1. Импорт угля (а) и газа (б) в январе - феврале 2017 2.

Не менее сложная ситуация с добычей, потреблением и импортом природного газа. По результатам 2016 г. (табл. 2) потребление природного газа Украины составило 30,3 млрд. куб. м. [5]. Для покрытия потребностей отечественного потребления использовался природный газ импортированный из Европы - 11,1 млрд. куб. м и собственной добычи - 20,2 млрд. куб.

В январе-феврале 2017 года Украина увеличила импорт природного газа на 30 \% (на 651,5 млн. куб. м) по сравнению с аналогичным периодом 2016 года - до
2 млрд. 819,8 млн. куб. м [5]. В том числе со стороны Словакии в январе-феврале было импортировано 2 млрд. 407,8 млн. куб. м, Венгрии - 179,9 млн. куб. м, Польши 232 млн. куб. м. (рис. 1, б).

Как видно, разница между потребностью отрасли и собственными ресурсами составляет более $30 \%$. Для покрытия дефицита страна вынуждена импортировать как природный газ, так и уголь. Разница должна покрываться за счет либо импорта, либо искать альтернативные решения.

Табл. 2. Потребление, добыча газа и угля в Украине

\begin{tabular}{|l|c|c|c|}
\hline \multicolumn{1}{|c|}{ Вид топлива } & Общее потребление & Собственная добыча & \multicolumn{1}{|c|}{ Импорт } \\
\hline \multicolumn{5}{|c|}{2016 г. } \\
\hline Газ, млрд. м
\end{tabular}


Годовой объем тепловой энергии, производимой в Украине, в 2016 г. составляет 97,5 млн. Гкал.

Основными потребителями тепловой энергии являются ЖКХ и население (около 70 \%), промышленность (20\%), другие отрасли экономики вместе потребляют около $10 \%$ теплоты [6].

Наряду с высоким показателем импортозависимости не менее серьезным обстоятельством является степень изношенности основных производственных мощностей энергогенерации, сетей теплоснабжения и низкой надежности и качества сетей передачи электроэнергии.

В 2016 г. энергетика Украины работала в форсированном режиме. Основную долю нагрузки несли атомные электростанции, технически задействована мощность которых увеличилась. По этой причине ряд профилактических работ пришлось срочно отложить.

Проектный срок эксплуатации энергоблоков АЭС составляет 30 лет. В ближайшие 10 лет он заканчивается для 12 блоков из 15, находящихся в эксплуатации. Продление срока эксплуатации еще на $15 \ldots 20$ лет базируется на снижении мощности блоков.

Bce 14 крупных ТЭС Украины работают на угле. Добыча антрацитового угля производится преимущественно на шахтах, которые находятся на территориях, подконтрольных т.н. «ДНР» и «ЛНР» и производственные мощности, которые обеспечивают добычу $1,5 \ldots 1,6$ млн. т антрацита в месяц, заблокированы.

Основными проблемами для энергетики Украины являются: $50 \%$ зависимость от импорта газа и угля, потеря контроля над большим количеством угледобывающих предприятий через оккупацию восточных областей, критический уровень износа генерирующих источников, недостаточный уровень внедрения новейших технологий .

В сложившейся ситуации энергонезависимость может быть осуществлена при условии глубокой модернизации существующих мощностей энергогенерации и инфраструктуры, сокращения показателя импортозависмости.

В настоящее время в мире интенсивно развивается направление развития возобновляемой энергетики. Особенно впечатляющим рост "чистой энергетики" (так возобновляемые источники называют в докладах Международного энергетического агентства - сокращенно МЭА) [8] произошел за последнее десятилетие. В период с 2006 года по 2015 год суммарные установленные мощности возобновляемой энергии выросли на $48 \%$. При этом мощности ветровой энергетики выросли почти в шесть раз, а солнечной - в 33 раза.

Европейский Союз - один из лидеров в развитии возобновляемых источников энергии. По оценке British Petroleum (BР), на его долю приходится более 37 \% мирового потребления возобновляемой энергии, в то время как на долю США - 20 \%, Китая - 17 \%. В двухтысячные годы в ЕС сформировалась полноценная политика стимулирования ВИЭ. В 2009 году была принята Директива 2009/28 по развитию возобновляемой энергетики, которая закрепила эту политику юридически.
С 2006 года по 2014 год общее производство возобновляемой энергии в ЕС выросло на $66 \%$, среднегодовой прирост составил 7,3\%. За последнее десятилетие ежегодные инвестиции в чистую энергетику составляли в среднем более 73 млрд. долл.

Германия стала первой развитой страной мира, peшившей со временем полностью отказаться от углеводородных и ядерных энергоносителей. Новая немецкая энергополитика, получившая название Energiewende ("энергетический разворот"), даст возможность предотвратить необратимые климатические изменения и обеспечить энергобезопасность страны.

Италия стала страной, которая закрыла все имевшиеся АЭС и полностью отказалась от ядерной энергетики. Бельгия, Германия, Испания, Швейцария, Тайвань осуществляют долгосрочную политику по отказу от ядерной энергетики. Польша по политическим и экономическим причинам остановила программы атомной энергетики и не завершила начатое строительство своих первых АЭС. В этих странах интенсивно развиваются возобновляемые источники энергии, в том числе геотермальные.

Австрия является одним из мировых лидеров по объему энергии, вырабатываемой альтернативными источниками, в общем объеме энергии, потребляемом государством. По итогам 2012 года $25 \%$ всей энергии, произведённой в Австрии, приходилось на возобновляемые источники, такие как ветровые электростанции, солнечная энергетика, биогаз и малые гидроэлектростанции. По прогнозам учёных уже в 2030 году Австрия может полностью, на $100 \%$, перейти на обеспечение собственных нужд за счёт возобновляемых источников энергии (ВИЭ) [9].

В Украине также существует острая необходимость поиска и использования альтернативных способов энергообеспечения на базе инновационных решений. Вместо восстановления и поддержания морально и физически устаревших технологий и оборудования, наряду с развитием атомной, тепловой и гидроэнергетики должно стать более широкое использование инновационных энергетических технологи, в том числе гео- и петротермальной энергетики, теплонасосных технологий.

На сегодняшний день из всех видов возобновляемых источников энергии наиболее коммерчески выгодной является геотермальная энергетика, самая конкурентоспособная с точки зрения экономической эффективности и с точки зрения стоимости. Это связано с тем, что в отличие от других возобновляемых источников энергии, геотермальная энергетика не зависит ни от климатических условий, ни от погодных условий, ни от суточных изменений, и как следствие - коэффициент использования геотермальных станций самый высокий. Геотермальные электростанции позволяют иметь коэффициент использования установленной мощности до $90 \%$, в отличие $25 \ldots 30 \%$ по ветру и солнцу. Два этих фактора влияют на то, что коммерческая эффективность геотермальных электрогенерирующих установок крайне высокая и поэтому в мире развивается довольно активно. 
Украина имеет значительные ресурсы геотермальной энергии, которые в тепловом эквиваленте превышают запасы традиционного энергетического топлива. По прогнозной оценке в верхнем 3-километровом слое земной коры недр Украины содержится 9,2 млрд. ГВт·ч. энергии, что эквивалентно почти 1000 трлн. м $^{3}$ газа, а в верхнем 10-километровом слое земной коры недр Украины содержится 19 млрд. ГВт.ч (эквивалент 2070 трлн. м $^{3}$ газа) (табл. 3).

Таблица 3. Общий энергетический потенциал геотермальной ресурсов Украины

\begin{tabular}{|c|c|c|}
\hline Энергетические ресурсы & $\begin{array}{c}\text { Величина энергетического } \\
\text { потенциала, ГВт·ч }\end{array}$ & $\begin{array}{c}\text { Энергетический } \\
\text { потенциал в газовом } \\
\text { эквиваленте, } \text { м }^{3} \\
\text { природного газа }\end{array}$ \\
\hline $\begin{array}{l}\text { Тепловой энергетический потенциал } \\
\text { термальных вод на глубине } 3 \text { км }\end{array}$ & 70 тыс. ГВт·ч & 7,5 млрд. м³ природного газа \\
\hline $\begin{array}{l}\text { Тепловой энергетический потенциал } \\
\text { геотермальных ресурсов Украины } \\
\text { с учетом теплоты сухих горных пород } \\
\text { на глубине } 3 \text { км и геотермальных } \\
\text { тепловых насосов }\end{array}$ & 9,2 млрд. ГВт·ч & 1000 трлн. м ${ }^{3}$ природного газа \\
\hline $\begin{array}{l}\text { Тепловой энергетический потенциал } \\
\text { геотермальных ресурсов Украины } \\
\text { на глубине до } 10 \text { км }\end{array}$ & 19,18 млрд. ГВт·ч & 2070 трлн. м³ природного газа \\
\hline
\end{tabular}

Как видно из приведенных данных, ресурсы геотермальной теплоты смогут обеспечить работу геотермальных электростанций (ГеоТЭС) общей мощностью до 200...250 тыс. МВт при глубинах бурения скважин до 7 км. Систем геотермального теплоснабжения общей мощностью до 1,2...1,5 млн. МВт при глубинах бурения скважин до 4 км. Период работы этих систем составляет до 50 лет. Это позволит замещать более 8,4 млрд. м ${ }^{3}$ газа в год, то есть почти 100 \% потребностей газа в ком- мунальную энергетику страны.

В Украине технически возможный потенциал использования геотермальной энергии составляет 53,58 млн. МВт ч часов и сосредоточен, главным образом, в Закарпатской, Прикарпатской, Полтавской, Харьковской областях. Этот потенциал позволяет реализовать мощности по производству тепловой энергии в объеме 12,4 ГВт и электроэнергии в 414 МВт.

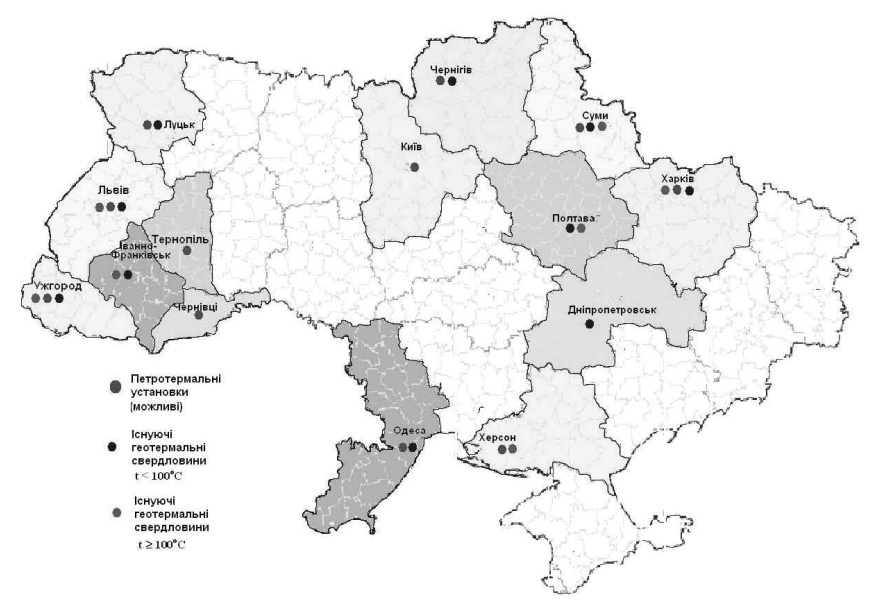

Рис. 2. Регионы Украины перспективные для развития геотермальной энергетики.

По прогнозной оценке ИТТФ НАН Украины технически доступный потенциал энергии геотермальных вод в 8-ми наиболее перспективных для внедрения областях Украины, составляет почти 16,68 тыс. ГВт•ч. в год. Это позволит производить около 13,5 тыс. ГВт· час. в год тепловой и 2,3 тыс. ГВт·час. в год электроэнергии, что эквивалентно уменьшению потребления природного газа на 2,2 млрд. $^{3}$ в год.
На территории газонефтяных месторождений имеется около 20 тысяч пробуренных законсервированных скважин. Для определения возможности использования этих скважин при создании геотермальных систем необходимо провести исследования: техническое состояние скважин, дебиты, температура теплоносителя и др. На основании полученных результатов определить техническую и экономическую целесообразность использо- 
вания их для создания геотермальных систем.

В перспективных 8 областях в год потребляется около 8,0 млн. т угля (7,0 т у. т.), тепловой энергии 1,8 т у. т. По расчетам тепловой потенциал геотермальной энергии в этих областях составляет 2,1 млн. т. у. т., что соответствует $30 \%$ от используемого угля.

В 2016 г. импорт угля в Украину составил в эквиваленте 9,2 млн. т у. т. Использование геотермальной энергии только в 8-ми областях (2,1 млн. т у. т.) сможет снизить импорт угля на $22 \%$.

Проблемой использования геотермального теплоносителя Институт технической теплофизики занимается с 60-х годов ХХ века. Академиками А.Н. Щербанём и А.А. Кремневым была предложена идея замкнутого контура - извлечение из земных глубин горячей воды, отбор ее теплоты и возвращение охлажденной воды в тот же водоносный горизонт (ГЦС). Впервые этот метод применен во Франции. Он так и называется «Украинский способ получения геотермальной энергии». Сейчас эта технология применяется во всем мире.

Доктор технических наук Шурчков А.В. с сотрудниками Института отработали технологию отбора теплоты из теплоносителя, имеющего высокую минерализацию. Итогом этой работы стало строительство Паужетской, Паратунской и Мутновской геотермальных электростанций на Камчатке. Была создана система моделирования процессов, протекающих под землей, для проектирования станций. В Институте были разработаны научные основы создания ГЦС. Были созданы опытно-промышленные и промышленные установки. В 1981 г. две опытно-промышленные геотермальные циркуляционные системы находились в эксплуатации на Ханкальском месторождении (г. Грозный), в 1983 г. в Сакском районе АР Крым. Совместно с Институтом «Атомтеплоэлектропроект» было начато проектирование геотермальных электростанций с подземными циркуляционными системами для трех районов: в Ставропольском крае, в Дагестане, в Закарпатье. Разработаны научные основы проектирования и создания циркуляционных систем отбора теплоты из сухих горных пород. Была разработана теория тепломассопереноса в природных и искусственно созданных геотермальных системах земной коры. Разработана методика геолого-экономической оценки петротермальных ресурсов.

В 1996 г. Институтом технической теплофизики была разработана Государственная целевая программа «Экологически чистая геотермальная энергетика», утвержденная КМ Украины №100 от 17.01.1996 г. В рамках данной программы построена станция в с. Медведевка (АР Крым), модернизирована станция в с. Янтарное (АР Крым), построены геотермальные установки в с. Берегово и Косино (Закарпатская обл.). Институтом были разработаны 6 проектов и бизнес-планов геотермальных станций для Закарпатья, Полтавской, Черниговской областей и АР Крым, были спроектированы и построены 12 геотермальных станций на территории Крымского полуострова. До настоящего времени работают 9 геотермальных станций: 3 в Закарпатье, 1 в Херсонской обл., 5 - в АР Крым.
После закрытия Программы в Украине прекратились все работы по использованию геотермальной энергии, в то время, когда наши ближайшие соседи широкими темпами изучают и внедряют геотермальные источники в энергетические системы своих стран. В РФ, которая является мощнейшим поставщиком газа, более 50 институтов занимаются изучением использования геотермальной энергии, в Беларуси работают около 100 теплонасосных геотермальных установок, в Прибалтийских странах начато внедрение ГеоТЭС, в Польше установленная мощность геотермальных станций составляла 98,84 МВт, 6 систем централизованного отопления установленной мощностью 82,2 МВт [10].

Во Франции установленная мощность геотермальных станций, включая геотермальные тепловые насосы, составляет 2 346,9 МВт, что позволяет сократить выбросы в атмосферу $\mathrm{CO}_{2}$ около 1,8 млн. тонн. В окрестностях Парижа 33 геотермальных установки отапливают 170 тысяч домов, получая эквивалентную экономию 144,4 млн. м³ природного газа. В 2015 году планируется запустить в эксплуатацию геотермальную централизованную систему мощностью 48 МВт, протяженностью 13 км, обеспечив отоплением и горячим водоснабжением 10 тысяч домов, сократив при этом выбросы $\mathrm{CO}_{2}$ на 14,6 тысяч т в год. Геотермальные тепловые станции должны обеспечить 60 \% потребности в теплоэнергии г. Парижа и его окрестностей [11].

В Европе, наряду с циркуляционными геотермальными станциями, нашли широкое применение геотермальные тепловые насосы. Их доля в производстве геотермальной теплоты составляет до 70 \%. В Украине эти технологии также слабо развиваются, несмотря на то, что они позволяют улучшить экологическую ситуацию и сократить расходы топлива.

Несмотря на сложившуюся в стране критическую ситуацию с энергетическими ресурсами, руководящие органы, профильные министерства, отраслевые институты не уделяют должного внимания развитию альтернативных источников энергии, в частности, геотермальной энергетики, не учитывают мировой опыт, не используют отечественные разработки. Выходом из сложившейся ситуации может быть создание Государственной программы развития альтернативных источников энергии, в т. ч. гео- и петротермальной энергии, что с учетом мирового и отечественного опыта позволит в короткие сроки нарастить мощности экологически чистой и экономически выгодной энергетики.

\section{ЛИТЕРАТУРА}

1. Енергетична галузь України: підсумки 2015 року [Электронный ресурс] - Режим доступа к ресурсу: www.razumkov.org.ua

2. Міністерство енергетики та вугільної промисловості Украӥни. Статистична інформація [Электронный ресурс] - Режим доступа к ресурсу: http://mpe.kmu.gov.ua

3. Інформаційна довідка про основні показники розвитку галузей паливно-енергетичного комплексу України за січень 2017 року (за фактичними даними) 
[Электронный ресурс] - Режим доступа к ресурсу: http://mpe.kmu.gov.ua

4. [Электронный ресурс] - Режим доступа к ресурcy: http://interfax.com.ua/news/economic/406585.html

5. ПАТ «УКРТРАНСГАЗ» [Электронный ресурс] Режим доступа к ресурсу: http://utg.ua

6. Паливно-енергетичні ресурси України [Электронный ресурс] - Режим доступа к ресурсу: www.ukrstat.gov.ua

7. Енергетична стратегія Украӥни до 2035 року "Безпека, енергоефективність, конкурентоспроможність" [Электронный ресурс] - Режим доступа к ресурcy: mpe.kmu.gov.ua/minugol/doccatalog

8. International Energy Agency. Statistics. [Элек- тронный ресурс] - Режим доступа к ресурсу: https://www.iea.org/

9. [Электронный ресурс] - Режим доступа к ресурcy: http://www.c-o-k.ru/market news/energetika-avstrii-k2030-godu-budet-polnost-yu-vozobnovlyaemoy

10. Beata Kepinska. Geothermal energy country update report from Poland, 2010 - 2014 [Электронный ресурс] Режим доступа к ресурсу: http://epp.eurostat.ec.europa. eu

11. French know-how in the field of geothermal energy. District heating and electricity generation systems [Электронный ресурс] - Режим доступа к ресурсу: www.ademe.fr

\section{CONTRIBUTION OF GEOTHERMAL ENERGY TO ENERGY INDEPENDENCE OF UKRAINE}

Dolinskiy A.A., Rezakova T.A.

Institute of Engineering Thermophysics of the National Academy of Sciences of Ukraine, 2a, Zhelyabova str., Kyiv, 03680, Ukraine

In the structure of the energy balance of Ukraine, the share of energy imports exceeds their own production and production, which puts the country in a serious dependence on imports, despite the fact that Ukraine has all the possibilities to fully provide itself with energy. To do this, it is necessary to increase the level of energy efficiency and promote the use of environmentally friendly renewable energy technologies in particular geothermal energy. Geothermal energy is an established and relatively mature form of commercial use of renewable energy sources. One of the important characteristics is the high load factor, which means that each MW of power produces significantly more electricity during the year than MW of wind or solar capacity.

Key words: energy balance, coal resources, geothermal energy.

1 The energy sector in Ukraine: results of 2015 [Electronic resource]. Resource Access: www.razumkov. org.ua

2. Ministry of Energy and Coal Industry of Ukraine.
Statistical information [Electronic resource]. Resource Access: http://mpe.kmu.gov.ua

3. Background of the main indicators of the fuel and energy complex of Ukraine for January 2017 [Electronic resource]. Resource Access: http://mpe.kmu.gov.ua

4. [Electronic resource]. Resource Access: http:// interfax.com.ua/news/economic/406585.html

5. PJSC "Ukrtransgaz" [Electronic resource]. Resource Access: http://utg.ua

6. PJSC "Ukrtransgaz" [Electronic resource]. Resource Access: www.ukrstat.gov.ua

7. Energy Strategy of Ukraine till 2035 "Safety, efficiency, competitiveness " [Electronic resource]. Resource Access: mpe.kmu.gov.ua/minugol/doccatalog

8. International Energy Agency. Statistics. [Electronic resource]. Resource Access: https://www.iea.org/

9. [Electronic resource]. Resource Access: http:// www.c-o-k.ru/market_news/energetika-avstrii-k-2030godu-budet-polnost-yu-vozobnovlyaemoy

10. Beata Kepinska. Geothermal energy country update report from Poland, 2010 - 2014 [Electronic resource]. Resource Access: http://epp.eurostat.ec.europa.eu

11. French know-how in the field of geothermal energy. District heating and electricity generation systems [Electronic resource]. Resource Access: www.ademe.fr

Получено 24.03.2017 Received 24.03.2017 